\title{
Praying with a patient constitutes a breach of professional boundaries in psychiatric practice
}

Rob Poole/Christopher C. H. Cook

\begin{abstract}
Summary
The extent to which religion and spirituality are integrated into routine psychiatric practice has been a source of increasing controversy over recent years. While taking a patient's spiritual needs into account when planning their care may be less contentious, disclosure to the patient by the psychiatrist of their own religious beliefs or consulting clergy in the context of treatment are seen by some as potentially harmful and in breach of General Medical Council guidance. Here, Professor Rob Poole and Professor Christopher cook debate whether praying with a patient
\end{abstract}

constitutes a breach of professional boundaries in psychiatric practice.

\section{Declaration of interest}

R.P. is an atheist / C.C.H.C. is in receipt of a grant from the Guild of Health; he is an Anglican priest and lectures in spirituality and pastoral studies at St John's College, Durham, and is Director of the Project for Spirituality, Theology and Health at Durham University. He is also Chair, Spirituality \& Psychiatry Special Interest Group, Royal College of Psychiatrists.

\section{For}

Praying with a patient in the course of clinical treatment constitutes an unequivocal breach of the boundaries of appropriate professional behaviour within the formal and informal codes of British psychiatric practice. ${ }^{1-3}$ This is true irrespective of whether prayer is a significant comfort to some people (as it unquestionably is). Whether prayers are answered (a more contentious question) is equally irrelevant. The reasons for this turn on the nature of boundaries in clinical practice.

Boundaries are important for two main reasons.

First, they protect patients from abuse. Doctors possess special expertise in the treatment of disease and in the relief of suffering. This expertise is not otherwise available, so that medical intervention is predicated on trust. This trust makes patients vulnerable to inappropriate behaviour by doctors. In clinical settings it is understood that the patient's needs are paramount and that the doctor's needs are set to one side. There has to be clarity over what is permissible behaviour between them. A wide range of otherwise socially acceptable behaviour is to be avoided or is strictly forbidden. This is not unique to the doctor-patient relationship. Very similar considerations apply to other health professions, and to other professions involving special expertise and trust, for example, the priesthood.

Second, medicine is mostly practised through the medium of the interaction between doctor and patient. This is particularly true in psychiatric practice, where the way that it is done is as important as what is done. ${ }^{4}$ The clinician brings their personality and a range of idiosyncrasies into the consultation. Adhering to clear boundaries is one of the ways by which treatment is optimised, preventing idiosyncrasies from running out of control. Patients have to be protected from disastrous errors that can follow from well-intended behaviour that fails to respect the unusually and intrinsically unequal nature of the relationship. Boundaries help to ensure that the relationship is therapeutic.

For example, there are strict boundaries over physical contact and sexual behaviour. These allow doctors to carry out the unusual and intimate touch that is necessary for assessment and treatment, while assuring patients that nothing untoward is happening. Commonplace social hugging and kissing lie outside of the boundary of everyday practice, while digital examination of the rectum is permitted where it is necessary, although absolutely taboo in ordinary social interaction. Unnecessary casual touch can open the door to abusive physical contact. Detailed discussion of patients' sexual life is appropriate where it is relevant. If it is not relevant to a clinical problem, then a detailed exploration is abusive. However, it is never appropriate for the clinician to discuss their own sexual life. Any form of actual sexual activity is a severe boundary violation, even if the patient requests or welcomes it.

Guarding boundaries is not easy. Violations tend to start with small slips that drift towards more serious problems. Boundaries must be drawn clear and close rather than fuzzy and wide. A boundary that is vague is not a boundary at all.

Like sexuality, spirituality and religion may need exploration where this is relevant to the patient's problem. Similarly, detailed disclosure of personal beliefs and actual religious activity in the consultation are inappropriate. Prayer is an activity based on profound personal convictions that have little to do with the practitioner's specific therapeutic expertise. Religion and spirituality are not special cases or exceptions with regard to boundaries. On the contrary, they are important exemplars of the need for clarity. The fact that some practitioners have a convinced faith means that patients need protection from certainties that are unrelated to psychiatric expertise. There are obvious and significant hazards in prayer, even where the patient and the doctor are of the same faith, or where the patient requests it.

Within any faith there are varying interpretations of doctrine and different understandings of the nature of God. For example, evangelical Christians vary considerably in their everyday tolerance of homosexuality. There can be major differences in the degree of emphasis on the redemptive elements of Christianity as opposed to the belief in a judgemental God who intervenes in everyday life, sometimes punitively. A shared faith does not guarantee a shared understanding of prayer. Such ambiguities create rich opportunities for therapeutic relationships to go wrong. A clinical relationship is bound to change as a consequence of joint prayer. Adverse consequences may take time to become evident. For example, patient and psychiatrist may differ over what it would mean for prayer to be answered. People with severe depression sometimes take unanswered prayer as a sign of divine abandonment. The direct involvement of the clinician can only complicate this. The integration of prayer into psychiatric 
treatment could reasonably be expected sometimes to have marked adverse consequences.

Even those who advocate praying with patients counsel caution, ${ }^{5}$ recognising some of the hazards. However, caution is not enough. Most boundary violations start with good intentions. Exercising caution is a basic responsibility of doctors. Caution does not move an inappropriate activity within the boundaries of acceptability. Prayer is personal and intimate; prayer does not rest upon our shared professional expertise; joint prayer will alter the therapeutic relationship; prayer and spiritual guidance can be provided by others with a legitimate religious role. These factors, taken individually and together, indicate that prayer is not the business of psychiatrists. On the contrary, it is inimical to our fundamental responsibilities.

We live in a diverse, pluralistic society. The idea that the positive power of prayer is more important than professional obligations (i.e. the implication that any religious faith is necessarily true and that it should be privileged over other beliefs) is unacceptable. Prayer is outside of respectable clinical practice in the UK in the 21 st century, and the only responsible position is simply not to do it.

Rob Poole

\section{Against}

The principles of good psychiatric practice in therapeutic relationships include self-awareness, respect of patient autonomy, sharing of knowledge, recognition of personal limitations, clarity about boundaries and roles, and mutual respect. ${ }^{3}$ Such principles may be observed for the good of the patient, or flouted to their disadvantage and harm, across various domains, including the sexual, financial, cultural, spiritual and religious. Among these domains, spirituality and religion have recently come to the fore as areas within which psychiatrists have differing and strongly held opinions as to exactly where the boundaries of good practice may be defined. ${ }^{6}$ Controversy about praying with patients, a practice on which we have little or no research evidence as to extent, nature or outcomes in the UK, is situated within this broader context of the place of spiritual care within overall mental healthcare provision.

The arguments for inclusion of spirituality within psychiatric assessment, treatment planning and service provision are concerned both with an evaluation of the research evidence and an acknowledgement of the views of service users, many of whom have been vocal in expressing their desire for spirituality to be addressed as an important part of their care. ${ }^{7-9}$ Although the former is a proper matter for scientific debate, the latter must be respected both individually and collectively as a part of the very fabric of good psychiatric practice. Such respect will properly be manifested both in circumstances in which patients do not wish to discuss their spiritual and religious beliefs as well as in circumstances in which they do. Whereas the former circumstances will provide a clear context within which an offer on the part of the psychiatrist to pray with their patient would be both disrespectful and unprofessional, the latter are both quite different and also much more complex. It is in these circumstances, where a patient either directly requests prayer or else might reasonably be expected to welcome it, that proper questions arise as to the nature, scope and boundaries of good psychiatric practice.

It is arguable that good practice requires that a psychiatrist who shares a patient's faith tradition, having discussed within the limits of their own professional competence the spiritual aspects of that patient's condition, and respecting the patient's informed wish to engage in prayer together, should then pray with them. Indeed, the question might be posed as to whether there would be proper ethical, professional or spiritual grounds to refuse to do so? Affirmative answers to that question might emerge in various forms. For example, matters of prayer and religious belief might form part of a delusional system, transference or counter-transference, compulsive or addictive behaviours, or other aspects of the psychiatric disorder at hand, which would at least indicate caution and further discussion, if not completely preclude the possibility of prayer as a part of good practice. Or else, ethical and theological objections might arise where a patient asks a psychiatrist to pray for something that the psychiatrist could not in good conscience pray for. In such circumstances, and also probably in most circumstances where psychiatrist and patient are from different faith traditions, the psychiatrist should properly refuse the request. But if we assume that such psychiatric, ethical and theological objections do not arise, then why may the psychiatrist not properly pray with their patient?

If it is being asserted that the psychiatrist may not pray with their patient even in circumstances where there are not specific contraindications, then it would seem that a boundary between the secular and the spiritual domains is being imposed. It has been suggested, for example, that psychiatrists are 'applied biopsychosocial scientists' and that spiritual matters are 'in a different domain from psychiatric practice. ${ }^{10}$ But even if a patient wants their psychiatrist to be a scientist, this does not mean that they do not also want them to be a human being who demonstrates integrity, compassion and spiritual awareness. Furthermore, secularity is a far from neutral domain within which to conduct the therapeutic encounter. It is deeply biased against transcendence. ${ }^{11}$ An intrusion of secularity into clinical practice in this way does not respect patient autonomy. It is an aberration of our secular age that prayer understood as relationship with the transcendent might be considered unprofessional.

A further, and even more fundamental, problem exists, however, in respect of any assertion that praying with a patient breaches professional boundaries. Prayer, even within a single faith tradition such as Christianity, is notoriously difficult to define and easily becomes all encompassing. Thus, for example, it has been suggested that prayer is 'primary speech . . . that primordial discourse in which we assert, however, clumsily or eloquently, our own being. ${ }^{12}$ To explore, either clumsily or with eloquence, the nature and experience of what it is to be his or her 'self' is at the heart of the psychiatric endeavour on behalf of the patient. As a form of self-awareness it demonstrates good psychiatric practice. For the Christian patient and psychiatrist (and I daresay also the Muslim, Jew or many others), prayer of the most fundamental kind will occur implicitly, even if not explicitly, at every therapeutic encounter. It is, in fact, completely unrealistic to attempt to exclude prayer understood in this way.

Good psychiatric practice requires respect for every patient's spirituality. Sometimes, the recognition of personal limitations, mutual respect, sharing of knowledge, self-awareness and respect for patient autonomy that constitute good practice will also constitute prayer.

Christopher C. H. Cook

\section{For: rebuttal}

Professor Cook's model of professional boundaries overemphasises an abstracted caring respectfulness while neglecting the need to manage the specific characteristics of therapeutic relationships. A 'holistic' expectation of attention to the transcendent in clinical 
practice may be well intentioned but it is neither appropriate nor harmless.

Cook suggests that the fact that some patients might welcome or desire prayer as part of treatment necessarily means that we should comply. However, it is a fundamental duty of doctors to decline to do things that patients want, but which we believe are inappropriate. Examples would include lending them money, prescription of opiates on demand, and the use of homeopathy in place of psychopharmacology in the treatment of schizophrenia. Complying with an inappropriate request is not respectful, it is a boundary violation. There is a huge difference between treating patients as partners in the therapeutic endeavour and simply doing anything that they might want. A significant part of psychiatric practice involves getting people to do things they are reluctant to do, because following the line of least resistance rarely leads to recovery. ${ }^{13}$

Cook seems to suggest that a shared faith offers some protection against boundary violations, but my example above involves a clinician and patient from the same religion. A shared faith offers no more protection with regard to religion than shared sexual orientation does with respect to sexual behaviour. His later comments regarding the nature of prayer seem to me to be a flawed reductio ad absurdum argument. There can be no objection to prayer that occurs implicitly or subliminally, any more than there can be an objection to implicit or unstated sexual attraction. It is when prayer is explicit and acted on within the relationship that a problem arises, just like sexual activity.

Cook attempts to turn my argument against prayer with patients on its head by suggesting that it is inappropriate for secularity to intrude into clinical practice. However, the General Medical Council (GMC) guidance on this matter is clear:

'You should not normally discuss your personal beliefs with patients unless those beliefs are directly relevant to the patient's care. You must not impose your beliefs on patients, or cause distress by the inappropriate or insensitive expression of religious, political or other beliefs or views. Equally, you must not put pressure on patients to discuss or justify their beliefs (or the absence of them). ${ }^{2}$

In the UK we are expected to practise within a secular framework, irrespective of our personal beliefs. Transcendence has to be dealt with away from the clinical setting. Some religious psychiatrists may regard this as an aberration, but we live in a pluralistic, secular age, and bringing religion, prayer and spirituality into clinical practice represents a change to accepted professional values. The burden of proof as to whether this is appropriate lies with those who want change.

Cook complains that secularity is not neutral. It is hard to know what true neutrality would look like with respect to religious faith. Clinical secularity attempts to retain a balanced position by understanding and respecting patients' religious beliefs while avoiding behaviour that contradicts fundamental professional obligations.

A major religious objection to secularity is that it does not privilege the beliefs of professionals who have a faith. A recent debate organised by the Spirituality and Psychiatry Special Interest Group of the Royal College of Psychiatrists on intolerant secularisation illustrated this. ${ }^{14}$ It emerged that some (but by no means all) Christian psychiatrists strongly object to secularism in clinical practice because they regard homosexual acts as sinful and they are prevented from bringing this attitude into their interactions with patients. Cook is correct that there can be no neutral position over this. Behaviour that appears to be homophobic is incompatible with the values of modern psychiatric practice. The fact that homophobia might be based on religious faith is irrelevant.

Similarly, a recent survey of British psychiatrists' beliefs on aetiological factors in depression and schizophrenia showed that a small number believe schizophrenia to be caused by supernatural factors. ${ }^{15}$ Psychiatrists can believe whatever they want, but it would be entirely wrong to allow them to bring a belief in supernatural aetiology into their work. Cook has argued that demons are real spiritual entities and that the possibility of actual demonic possession should be taken into account in clinical assessment. ${ }^{16}$ I have no idea whether he still holds this view, but I have no doubt that others do. Many psychiatrists with a faith would agree with me that such concepts have no place in modern psychiatric practice.

Allowing prayer in clinical practice is bound to bring the baggage of religion with it, which sometimes will mean intolerance of certain lifestyles and aetiological beliefs that are incompatible with science or rationality. If we allow prayer into clinical practice, then how can we prevent prayers that are highly inappropriate in that setting (for protection against demonic attack, or for deliverance from homosexuality or involving any other idiosyncratic idea that the practitioner feels to be part of their faith)?

Secularity may not be entirely neutral, given the diversity of belief in our society. However, it is the only appropriate position that can be taken to protect patients in clinical practice.

Rob Poole

\section{Against: rebuttal}

Professor Poole and I have significant areas of agreement.

1 There are situations within which clinical and professional judgement would suggest that prayer with patients is inappropriate or contraindicated. Psychiatrists should therefore not necessarily comply with requests for prayer.

2 Some kinds of prayer are not objectionable: for example, the implicit or 'subliminal'.

3 Boundaries in the therapeutic relationship are important and should be observed. Pressure should not be placed on patients to pray and the (religious or other) beliefs of the psychiatrist should not intrude on clinical assessment or treatment so as to violate patient autonomy or professional integrity.

Clearly, we also have significant areas of disagreement. Although Poole considers GMC guidance to offer a clear boundary excluding prayer, Personal beliefs and medical practice also advises that:

'Discussing personal beliefs may, when approached sensitively, help you to work in partnership with patients to address their particular treatment needs. You must respect patients' right to hold religious or other beliefs and should take those beliefs into account where they may be relevant to treatment options.'

Poole also asserts that psychiatric practice in the UK is 'expected' to be within a secular framework. However, Good Psychiatric Practice requires that:

'a psychiatrist must recognise and respect the diversity of patients' lifestyles, including cultural issues, religious and spiritual beliefs, ambitions and personal goals. $^{\prime 17}$

This would appear to be a patient-centred, rather than a secular, framework. The burden of proof for variation of accepted practice therefore lies with the psychiatrist who does not wish to observe this patient-centred approach, for example by allowing secularity to intrude on the therapeutic relationship, rather than with the psychiatrist who judges that in occasional instances prayer with a patient might be appropriate.

Topics such as homophobia and demon possession are among those that need to be handled sensitively and respectfully in any consultation. Clearly, the former is to be eschewed. What I am advocating does not conflict in any way with the College position statement on sexual orientation. ${ }^{18}$ The important consideration here is that the content of prayer must be professionally as well 
as theologically appropriate and should not violate boundaries, whether sexual or otherwise.

Although I would write a paper on demon possession and mental illness differently today than I did 13 years ago, I said neither that 'demons are real spiritual entities' nor that clinical assessments should take into account 'the possibility of actual demonic possession'. I urged rather that, when making clinical assessments, doctors should 'not neglect the spiritual dimension of life. ${ }^{16}$ In the Church of England, psychiatric assessment and advice is seen as an integral part of good practice in managing deliverance ministry (including 'exorcism') ${ }^{19}$ and provides an example of an area where (even if the psychiatrist is not involved in the actual prayers) it is not realistic to neatly separate out the spiritual from the psychological, social and biological dimensions of the human condition. Belief in demon possession is an important aspect of the cultural context of mental illness in many Christian, Islamic and other communities in the UK. A patientcentred response to this context should not neglect the part played by prayer. This is not at all incompatible with either scientific or professional integrity, although doubtless prayers will more usually be offered by other members of the faith community than the psychiatrist.

It is true that more scientific research is needed on prayer and mental disorder. I am not aware of any research on the specific topic of psychiatrists praying with their patients. However, there is evidence that prayer provides a positive coping resource. In one study of out-patients with DSM-IV depression, patients who participated in six weekly sessions of prayer with a lay minister showed significant improvements in depression and anxiety in comparison with controls. ${ }^{20}$ In another study, of elderly male medical in-patients, religious thought and/or activity (within which, prayer seems to have been a significant component) was reported by patients as an important coping strategy and predicted lower scores on depression scales at follow-up. ${ }^{21}$

Poole has helpfully clarified that it is prayer that is 'explicit and acted on within the relationship' that he believes leads to problems. I take this to mean prayer spoken out loud by the psychiatrist during the consultation. If so, then this would allow prayer spoken by the patient, silent prayer, implicit prayer, and subliminal prayer, as important exceptions to any blanket proscription. Presumably it also allows prayer spoken when the patient is not present and non-theistic practices similar to prayer, such as mindfulness? This leaves a narrow restriction of practice of uncertain benefit which makes little theological, spiritual, scientific or professional sense. Exactly why may God not be addressed, out loud, by the psychiatrist during a consultation, with a patient who desires this, where there are no specific contraindications, and where there are clear professional, culturally and religiously sensitive reasons for believing that it might be helpful?

\section{Christopher C. H. Cook}

\section{For: conclusion}

Professor Cook and I appear to have some irreconcilable differences of opinion. We even disagree as to the extent of our disagreement. The fundamental issue of contention cannot be resolved by dismissing it as subtle and meaningless.

Psychiatry is not the only (or necessarily the most important) way of helping people with mental illness. It does have a distinctive and particular role. It can only be successful when practiced within clear and defined boundaries. Turning psychiatry into a generic boundary-less melange of everything that might conceivably be helpful would undermine our effectiveness and open the door to all manner of abusive and damaging practice. This is unnecessary. For example, people can benefit from prayer through religious practice, where religious leaders' affiliations and beliefs are transparent and are not cluttered by a professional standing predicated on scientific legitimacy.

Readers can decide for themselves whether Cook's evidence for the effectiveness of prayer justifies its use in clinical settings. They can also judge whether I have misinterpreted GMC guidance or misconstrued Cook's paper on demon possession. However, in advocating prayer, he has not suggested how patients can be protected from the introduction of values that are based on religious, rather than professional, imperatives. The concern is not hypothetical. In a study of American psychiatrists with an evangelical Christian belief, almost a third said that they discouraged patients who were non-believers from abortion, homosexual acts and premarital sex. ${ }^{22}$

Like other professions, psychiatry has sometimes been guilty of abusive and damaging practice. We have made considerable progress in reforming ourselves, particularly with regard to our attitudes to service users and their organisations. However, there is a growing concern that, in attempting to respond positively to constructive criticism, we have neglected to defend some essential elements of psychiatric practice. Examples include the biomedical underpinnings of the profession ${ }^{23}$ and the organisation of services. ${ }^{24}$ The integration of prayer and other religious practices into clinical work raises similar concerns over well-meant but fundamentally ill-conceived change. My debating style may seem strident to some, but my fear that such a change could have far-reaching negative consequences is based on widely accepted principles of clinical practice unrelated to personal atheism. ${ }^{4}$

Cautiously applied prayer and all other active expressions of religious practice are wrong in clinical settings, because there are tangible risks (which Cook acknowledges), any benefits of prayer can be secured in more appropriate settings and there is no evidence base to fall back on (although I would have concerns about the ethics of conducting such research). Most importantly, Cook can offer no mechanism to protect patients from religious abuse or unwitting harm, other than the practitioner's judgement and good will. This question is important and should be the subject of wider debate.

Rob Poole

\section{Against: conclusion}

Good Psychiatric Practice is dependent on relationships characterised by 'respect, openness, trust and good communication' as much as, arguably more than, 'scientific legitimacy'. Where the psychiatrist or patient is a person of faith, it will often be difficult to divorce such relationships from the matter of prayer. In my experience such prayer only rarely needs to be made explicit, and I have therefore wondered why I felt the need to engage in this debate. I have done so because I believe that prayer is too important to allow it to be arbitrarily excluded, misunderstood or abused in psychiatric practice. As currently worded, the motion states that my silent or implicit prayers with and for virtually all of my patients are a breach of professional boundaries. Even modified by the word 'explicitly', it fails to reflect understanding of the respect, openness, trust and communication that are at the heart of true prayer.

The position that I have outlined accords with Good Medical Practice and Good Psychiatric Practice and recognises the importance of clearly defined, but openly debated, professional boundaries. It adopts a patient-centred framework. I have 
suggested a variety of circumstances within which it would clearly be inappropriate and unprofessional for a psychiatrist to pray with a patient, including those where it might undermine trust in the doctor-patient relationship and/or be deleterious to the patient's well-being.

There has not been space to explore the variety of different definitions or methods of prayer that exist. However, I think that we have clarified that it is an 'explicit' kind of prayer, during the clinical consultation, which causes potential concern. Were the net to be drawn more widely, and mental or silent prayer included, most and perhaps all religious doctors would effectively be excluded from practice. But if it is to be drawn narrowly, perhaps it can simply be defined as conversation with God.

Professor Poole has rightly drawn attention to the possibility of abuse - although this exists in any consultation. Some topics would not be appropriate matters for prayer, especially where these cross professional or ethical boundaries or are incompatible with the spiritual traditions and beliefs of patient or doctor. Homophobia, for example, is no less (I think more) unacceptable for being expressed in prayer rather than in ordinary conversation. In the study by Gallanter et $a b^{22}$ quoted by Poole, I would agree that the advice given by the psychiatrists concerned was unprofessional. However, it is irrelevant whether it was expressed in prayer or not. It is what is said that here defines breaches of professional boundaries, not the addressing of the conversation to God. It is not prayer that is unprofessional, but the expression of certain beliefs, values or views.

I cannot see how prohibiting prayer would prevent either religious abuse or unwitting harm. Rather, guidance is required which clarifies the nature of good practice. I would suggest that prayer with patients, like all good clinical practice, should not exploit their vulnerability, cause them harm or distress, or be judgemental. It should not be used by the psychiatrist as an opportunity to foist their own views and beliefs upon their patient, or to legitimise their authority, and should only take place if it is compatible with full respect for the views and beliefs of the patient. It should be documented in the notes and, if there is any doubt, discussed with a supervisor or colleague. It should only be undertaken with consent, normally by request of the patient, and no pressure should be exerted for it to occur.

Christopher C. H. Cook

\section{Acknowledgement}

The views expresed here by C.C.C.H. are his own; the Spirituality and Psychiatry Special Interest Group of the Royal College of Psychiatrists does not adopt any particular position in relation to the matters debated here.

For: Rob Poole, MB BS, FRCPsych, Department of Mental Health, Glyndŵr University, Croesnewydd Road, Wrexham LL13 7YP, UK. Email: rob.poole@wales.nhs.uk

Against: Christopher C. H. Cook, MD, FRCPsych, Department of Theology \& Religion, Durham University, Abbey House, Palace Green, Durham DH1 3RS, UK. Email: c.c.h.cook@durham.ac.uk

\section{References}

1 General Medical Council. Good Medical Practice: duties of a doctor. GMC, 2011 (http://www.gmc-uk.org/guidance/good_medical_practice/ duties_of_a_doctor.asp).

2 General Medical Council. Personal beliefs and medical practice - guidance for doctors. GMC, 2008 (http://www.gmc-uk.org/guidance/ethical_guidance/ personal_beliefs.asp).

3 Jarrett $P$, Milaviè G, Roy A. Vulnerable Patients, Safe Doctors: Good Practice in our Clinical Relationships (College Report CR146). Royal College of Psychiatrists, 2007.

4 Poole R, Higgo R. Psychiatric Interviewing and Assessment. Cambridge University Press, 2006.

5 Koenig HG. Religion and mental health: what should psychiatrists do? Psychiatr Bull 2008; 32: 201-3.

6 Dein S, Cook $\mathrm{CCH}$, Powell A, Eagger S. Religion, spirituality and menta health. Psychiatrist 2010; 34: 63-4.

7 Koenig HG. Research on religion, spirituality, and mental health: a review. Can J Psychiatry 2009; 54: 283-91.

8 McCord G, Gilchrist VJ, Grossman SD, King BD, McCormick KF, Oprandi AM, et al. Discussing spirituality with patients: a rational and ethical approach. Ann Fam Med 2004; 2: 356-61.

9 Nicholls V. Taken Seriously: The Somerset Spirituality Project. Mental Health Foundation, 2002.

10 Poole R, Higgo R, Strong G, Kennedy G, Ruben S, Barnes R, et al. Religion, psychiatry and professional boundaries [letter]. Psychiatr Bull 2008; 32 356-7.

11 Taylor C. A Secular Age. Belknap, 2007

12 Ulanov A, Ulanov B. Primary Speech: A Psychology of Prayer. Westminster John Knox Press, 1985

13 Poole R, Higgo R. Clinical Skills in Psychiatric Treatment. Cambridge University Press, 2008.

14 Spirituality and Psychiatry Special Interest Group. Newsletter No. 30 December 2008. Royal College of Psychiatrists (http://www.rcpsych.ac.uk/ members/specialinterestgroups/spirituality/publicationsarchive/ newsletter30.aspx).

15 Baillie D, McCabe R, Priebe S. Aetiology of depression and schizophrenia: current views of British psychiatrists. Psychiatr Bull 2009; 33: 374-7.

16 Cook C. Demon possession and mental illness. Nucleus 1997; Autumn: 13-7 (http://www.cmf.org.uk/literature/content.asp?context=article\&id=619).

17 Royal College of Psychiatrists. Good Psychiatric Practice (Third Edition) (College Report CR154). Royal College of Psychiatrists, 2009.

18 Royal College of Psychiatrists. Royal College of Psychiatrists' Position Statement on Sexual Orientation. PS01/2010. Royal College of Psychiatrists, 2010.

19 Perry M (ed). Deliverance : Psychic Disturbances and Occult Involvement (2nd edn). SPCK Publishing, 1996.

20 Koenig HG, Cohen HJ, Blazer DG, Pieper C, Meador KG, Shelp F, et al. Religious coping and depression among elderly, hospitalized, medically ill men. Am J Psychiatry 1992; 149: 1693-700.

21 Boelens PA, Reeves RR, Replogle WH, Koenig HG. A randomized trial of the effect of prayer on depression and anxiety. Int J Psychiatry Med 2009; 39: 377-92.

22 Gallanter M, Larson D, Rubenstone E. Christian psychiatry: the impact of evangelical belief on clinical practice. Am J Psychiatry 1991; 148: 90-5.

23 Craddock N, Antebi D, Attenburrow MJ, Bailey A, Carson A, Cowen P, et al. Wake-up call for British psychiatry. Br J Psychiatry 2008; 193: 6-9. 24 Burns T. The dog that failed to bark. Psychiatrist 2010; 34: 361-3. 